\title{
Gene Profiling of Aortic Valve Interstitial Cells under Elevated Pressure Conditions: Modulation of Inflammatory Gene Networks
}

\author{
James N. Warnock, ${ }^{1,2}$ Bindu Nanduri, ${ }^{3}$ Carol A. Pregonero Gamez, ${ }^{1}$ Juliet Tang, ${ }^{2}$ \\ Daniel Koback, ${ }^{1}$ William M. Muir, ${ }^{4}$ and Shane C. Burgess ${ }^{2,3}$ \\ ${ }^{1}$ Department of Agricultural and Biological Engineering, Mississippi State University, Mississippi State, MS 39762, USA \\ ${ }^{2}$ Life Science and Biotechnology Institute, Mississippi State University, Mississippi State, MS 39762, USA \\ ${ }^{3}$ Department of Basic Sciences, Mississippi State University, Mississippi State, MS 39762, USA \\ ${ }^{4}$ Department of Animal Sciences, Purdue University, West Lafayette, IN 47907, USA
}

Correspondence should be addressed to James N. Warnock, jwarnock@abe.msstate.edu

Received 7 March 2011; Revised 6 June 2011; Accepted 16 June 2011

Academic Editor: Adrian Chester

Copyright ( $) 2011$ James N. Warnock et al. This is an open access article distributed under the Creative Commons Attribution License, which permits unrestricted use, distribution, and reproduction in any medium, provided the original work is properly cited.

\begin{abstract}
The study aimed to identify mechanosensitive pathways and gene networks that are stimulated by elevated cyclic pressure in aortic valve interstitial cells (VICs) and lead to detrimental tissue remodeling and/or pathogenesis. Porcine aortic valve leaflets were exposed to cyclic pressures of 80 or $120 \mathrm{mmHg}$, corresponding to diastolic transvalvular pressure in normal and hypertensive conditions, respectively. Linear, two-cycle amplification of total RNA, followed by microarray was performed for transcriptome analysis (with qRT-PCR validation). A combination of systems biology modeling and pathway analysis identified novel genes and molecular mechanisms underlying the biological response of VICs to elevated pressure. 56 gene transcripts related to inflammatory response mechanisms were differentially expressed. TNF- $\alpha$, IL- $1 \alpha$, and IL- $1 \beta$ were key cytokines identified from the gene network model. Also of interest was the discovery that pentraxin 3 (PTX3) was significantly upregulated under elevated pressure conditions (41-fold change). In conclusion, a gene network model showing differentially expressed inflammatory genes and their interactions in VICs exposed to elevated pressure has been developed. This system overview has detected key molecules that could be targeted for pharmacotherapy of aortic stenosis in hypertensive patients.
\end{abstract}

\section{Introduction}

The pathogenesis of aortic stenosis (AS) is a largely understudied research area, compared to other cardiovascular diseases, which has major human health implications. Historically, AS has been considered an age-related, passive, degenerative disease. However, during the past 15 years, indisputable evidence has shown that AS is an active, cellmediated process. Nonrheumatic AS is characterized by chronic inflammation, increased extracellular matrix (ECM) remodeling, proliferation, and differentiation of valvular interstitial cells (VICs) and the development of calcific lesions on the valve $[1,2]$. Nonrheumatic AS is preceded by aortic sclerosis, a condition of valve thickening in which left ventricular outflow is not obstructed. Aortic sclerosis is associated with a 50\% increase in death from all cardiovascular causes and increases the risk of myocardial infarction, heart failure, and stroke [3]. Progressive AS, in which obstruction to left ventricle outflow is present, produces left ventricular hypertrophy, left ventricular diastolic and systolic dysfunction, congestive heart failure, angina, arrhythmias, and syncope [4]. Severe symptomatic AS is associated with a life expectancy of less than 5 years [5]. In 2009, AS was directly responsible for over 13,752 American deaths and was an underlying factor in an additional 27,380 deaths and 49,000 hospital discharges. Though the disease is associated with significant clinical consequences, there is currently no effective therapy for valve disease other than surgical aortic valve replacement [6]. 
In vivo studies have shown that a causal link exists between hypertension and AS [7]. This is supported by numerous in vitro studies that have shown that elevated cyclic pressure plays an important role in valve ECM synthesis, proinflammatory and cathepsin gene expression [8-11]. In addition, it has been reported that transvalvular pressure has a direct effect on VIC stiffness and collagen synthesis [12]. The potential mechanisms connecting hypertension with initiation and progression of aortic valve disease include (1) hypertensive pressure raises the diastolic transvalvular pressure across the valve, increasing the mechanical strain experienced by the leaflets; (2) hypertension may disturb the hemodynamic environment (i.e., compression of the ECM, altered flow patterns), thus influencing valve cell behavior; and (3) hypertension may play a key role in the activation of several biological processes that induce aortic valve remodeling and disease [13].

We present here the first study of VIC gene expression profiling in an ex vivo model of elevated cyclic pressure. The data generated have enabled us to identify mechanosensitive gene networks, and we have also investigated VIC expression of a subset of genes associated with inflammation. It was hypothesized that expression of several proinflammatory genes, such as TNF- $\alpha$ and IL-6, would be significantly increased as clinical studies have shown these to colocalize with calcific regions in explanted aortic valves from prehypertensive patients [14]. TNF- $\alpha$ has also been associated with matrix remodeling through the expression of MMP-1 and -3 [15]. Additionally, TNF- $\alpha$ and other cytokines, such as IL- $1 \beta$, express enzymes generating oxidants $\left(\mathrm{O}_{2}{ }^{-}\right)$capable of promoting low-density lipoprotein (LDL) oxidation [16]. Proteoglycans trap LDL in the tissue, and oxidative modification leads to endothelial expression of adhesion molecules (ICAM-1 and VCAM-1) and chemoattractants (MCP-1).

\section{Materials and Methods}

2.1. Tissue Harvest. Aortic valves were collected from six individual female Yorkshire/Hampshire pigs immediately after death. Animals were less than 6 months of age with a postslaughter weight of no more than $120 \mathrm{lbs}$ (Sansing Meat Services, Maben, MS). Valves were rinsed twice in icecold sterile Phosphate Buffer Saline (PBS, Sigma, St Louis, $\mathrm{MO}$ ) and transported to the laboratory on ice. Leaflets were cut one third of the distance from the annulus. Valve leaflets did not show any sign of degeneration, tearing or calcification. To ensure that only valve interstitial cells (VICs) were present in each sample, the endothelial cell layer was removed from each leaflet surface by immersion of valve tissue in collagenase II $(2 \mu \mathrm{g} / \mathrm{mL}$ in serum free DMEM, Worthington Biochemical Corp.) for 5 minutes at $37^{\circ} \mathrm{C}$ and $5 \% \mathrm{CO}_{2}$. The leaflet surface was then gently swabbed. Confirmation that the EC had been removed was done through Hemotoxylin and Eosin staining (Figure 1). Valve leaflets were rinsed twice with PBS to remove excess collagenase II before being incubated overnight in DMEM supplemented with 10\% Fetal Bovine Serum (FBS; Hyclone, Logan UT) and 1\% antibiotic/antimycotic solution (Sigma). The tissue had approximate dimensions of $12 \mathrm{~mm} \times 15 \mathrm{~mm}$.

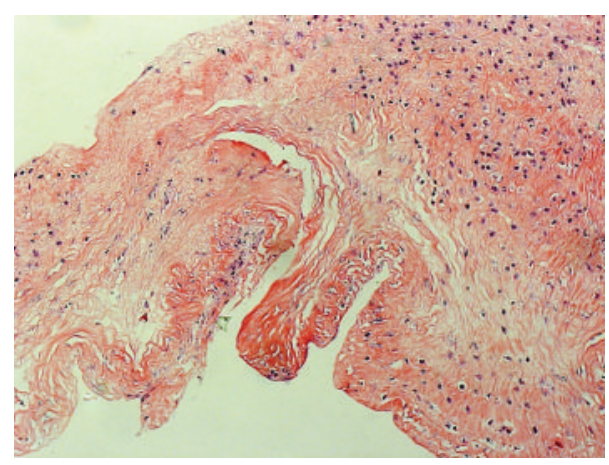

(a)

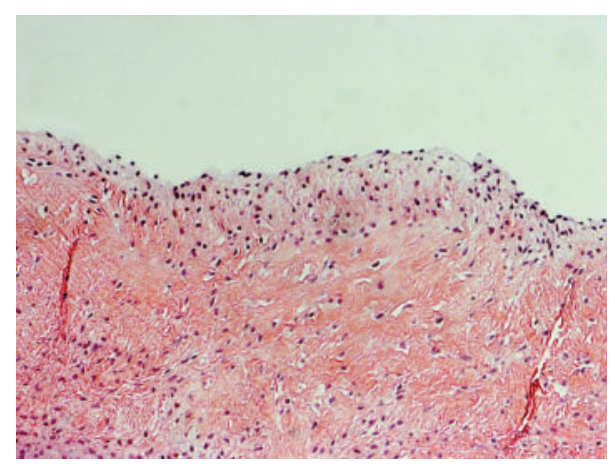

(b)

Figure 1: (a) H \& E stain of a valve leaflet, confirming that the endothelium has been removed by 5 -minute incubation with collagenase II followed by gentle swabbing. (b) Positive control sample showing an intact endothelium on a valve leaflet not treated with collagenase II and gentle swabbing. 10x magnification.

2.2. Pressure Studies. To investigate the effects of cyclic pressure, a custom-made, computer-operated dynamic pressure system was used. A schematic diagram and photos of the system are shown in Figure 2. Similar ex vivo systems have been used in the past to demonstrate changes in extracellular matrix protein synthesis and remodeling under elevated pressure conditions $[8,11]$. Additionally, this system has been used to demonstrate a correlation between elevated pressure and proinflammatory gene expression in aortic valve interstitial cells [9]. Leaflet tissue was placed in a sixwell tissue culture plate and immersed in $3 \mathrm{ml}$ of culture medium. The tissue culture plates were placed in the pressure chamber and exposed to cyclic pressures of $80 \mathrm{mmHg}$ or $120 \mathrm{mmHg}$, corresponding to diastolic transvalvular pressure in normotensive and hypertensive conditions [17], respectively, at a frequency of $1 \mathrm{~Hz}$ (sinusoidal wave; $0.6 \mathrm{sec}$ influx, $0.4 \mathrm{sec}$ outflux) for 24 hours. Figure 3 shows representative waveforms. At low-pressure conditions, pressure cycled between $35 \mathrm{mmHg}$ and $80 \mathrm{mmHg}$, with amplitude of $45 \mathrm{mmHg}$. Under elevated pressure conditions, the maximum pressure was $120 \mathrm{mmHg}$ and the minimum was $25 \mathrm{mmHg}$, providing amplitude of $95 \mathrm{mmHg}$. The pressure system exposed tissues to mechanical stimulation by increasing the air pressure above the supernatant media. To produce a change in the pressure within the chamber, the pneumatic piston moved downward in the chamber space, 


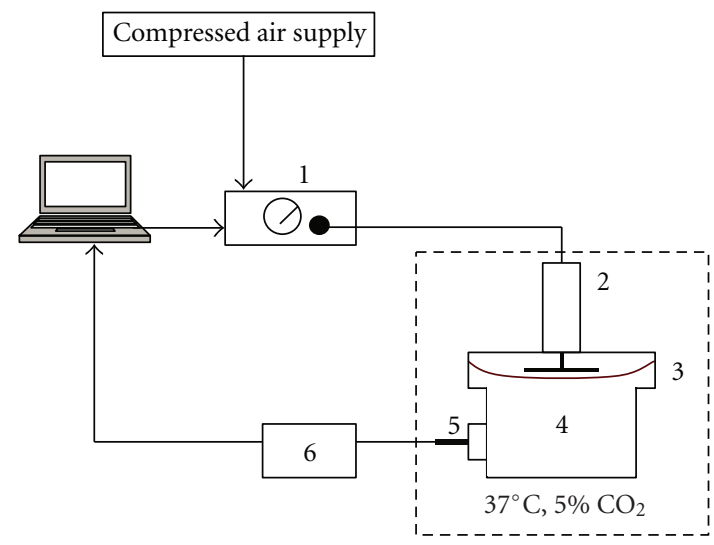

(1) Electropneumatic regulator

(2) Pneumatic cylinder

(3) Silicone membrane

(4) Pressure chamber containing tissue culture plate

(5) Pressure transducer

(6) Load cell conditioner

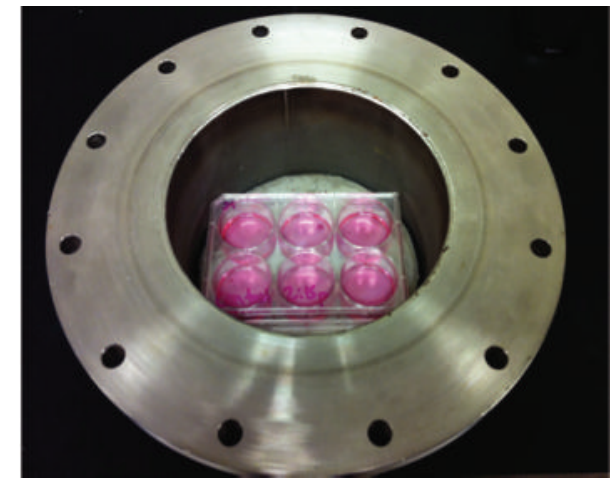

(b)

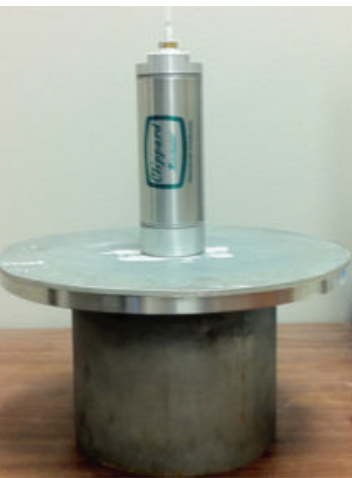

(c)

Figure 2: (a) Schematic diagram of the pressure system. A computer controls an electropneumatic regulator (1), controlling the flow of compressed air to a pneumatic cylinder (2) the cylinder exerts a compressive force on a silicone membrane (3) reducing the volume in the pressure chamber (4) and subsequently increasing the atmospheric pressure surrounding the leaflets that are in tissue culture plates in the chamber. A pressure transducer (Omega Engineering, Inc, PX302-200GV) (5) records the internal pressure of the chamber, which is relayed back to the computer via a load cell conditioner (Encore Electronics, Inc., Model 4025-101) (6). The voltage and the pressure signal were acquired with a data acquisition card module (Measurement Devices, PMD1608) and monitored using an in-house developed LabVIEW graphical user program (LabVIEW, National Instruments). The system was placed inside an incubator to maintain a $37^{\circ} \mathrm{C}$, $5 \%$ $\mathrm{CO}_{2}$ humidified atmosphere. (b) Photograph of a six-well plate in the pressure chamber before being sealed. (c) Photograph of the sealed pressure chamber prior to being place in the $37^{\circ} \mathrm{C}$ incubator.

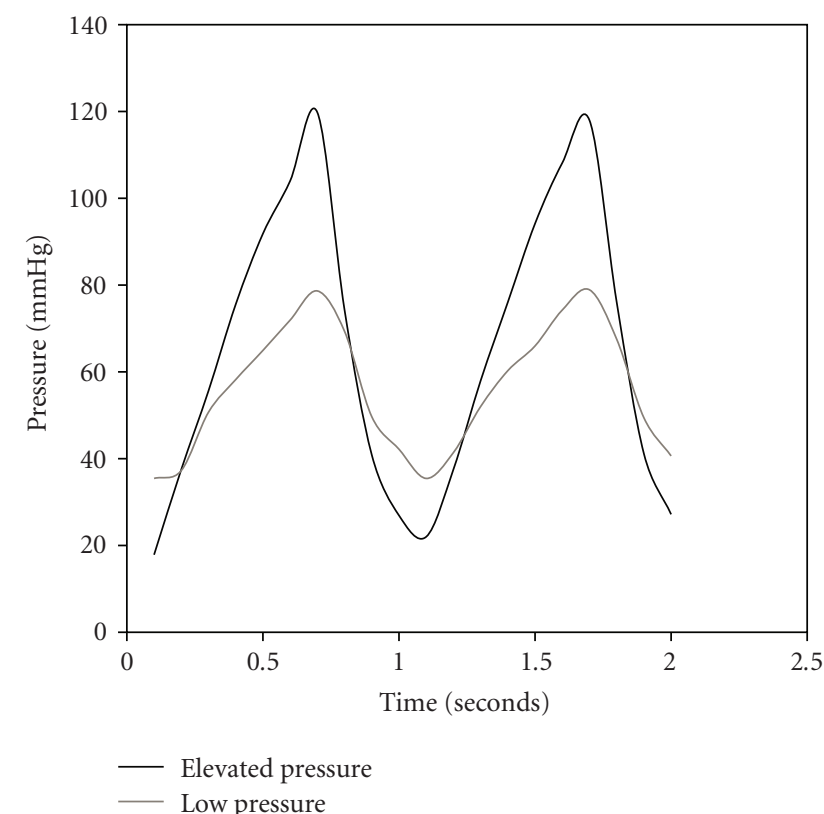

FIGURE 3: Pressure waveforms generated from the pressure system.

and the silicone gasket was stretched downward, reducing the volume of the chamber, and increasing the air pressure. During experiments, the pressure chamber was placed in an incubator at $37^{\circ} \mathrm{C}$. The $\mathrm{pH}$ of the culture medium was measured prior to and after each test using a $\mathrm{pH}$ meter. $\mathrm{pH}$ readings of culture medium ranged between 7.3-7.4, indicating no significant changes. Each experimental group contained three biological replicates.

2.3. Array Experiments. Upon completion of pressure experiments, each leaflet was rinsed twice with sterile PBS, submerged in $1 \mathrm{~mL}$ of RNA later RNA Stabilization Reagent (Qiagen) to avoid changes in RNA expression and stored at $-80^{\circ} \mathrm{C}$ until RNA extraction. Total RNA from porcine aortic valve interstitial cells (VICs) was extracted using the RNeasy Mini kit (Qiagen, Valencia, CA) following the manufacturer's instructions and stored at $-80^{\circ} \mathrm{C}$. The quantity and quality of RNA was confirmed by spectrophotometry (A260/A280 ratio) and capillary electrophoresis (2100 Bioanalyzer; Agilent Technologies, Palo Alto, CA) by using an RNA 6000 Picochip kit. Target preparation for microarray analysis was performed according to the manufacturer's established protocol (www.affymetrix.com). Briefly, a total of $100 \mathrm{ng}$ of RNA from each sample was used for single-stranded cDNA synthesis with SuperScript II reverse transcriptase and T7-Oligo(dT) primer/Poly(A) controls (Affymetrix, Santa Clara, CA). The single-stranded cDNA was then converted to double-stranded cDNA by using Escherichia coli DNA polymerase I (Affymetrix) for the first cycle. From template cDNA, biotin-labeled cRNA was prepared in an in vitro 
TABLe 1: Primer sequences used for qRT-PCR.

\begin{tabular}{|c|c|c|c|}
\hline Gene & GenBank accession no. & Primer sequence & Size (bp) \\
\hline MMP-3 & NM_001166308.1 & $\begin{array}{l}\text { 5'-TGTGGAGTTCCTGATGTTGG-3' (F) } \\
5^{\prime} \text {-GGCTGAAGTCTCCGTGTTCT-3' (R) }\end{array}$ & 240 \\
\hline MMP-1 & NM_001166229 & $\begin{array}{l}5^{\prime}-\text { TTTCCTGGGATTGGCAAC-3' (F) } \\
5^{\prime} \text {-TCCTGCAGTTGAACCAGCTA-3'(R) }\end{array}$ & 233 \\
\hline IL-6 & NM_214399.1 & $\begin{array}{l}5^{\prime} \text {-CACCAGGAACGAAAGAGAGC-3'(F) } \\
5^{\prime} \text {-GTTTTGTCCGGAGAGGTGAA-3' }(\mathrm{R})\end{array}$ & 204 \\
\hline PTX3 & NM_002852.3 & $\begin{array}{l}\text { 5'-GGGACAAGCTCTTCATCATGCT-3' (F) } \\
5^{\prime} \text {-GTCGTCCGTGGCTTGCA-3' (R) }\end{array}$ & 71 \\
\hline TNF- $\alpha$ & NM_214022.1 & $\begin{array}{l}5^{\prime} \text {-GAAGACACACCCCCGAACAGGCA-3'(F) } \\
5^{\prime} \text {-ACGTGGGCGACGGGCTTATCT-3'(R) }\end{array}$ & 379 \\
\hline
\end{tabular}

transcription (IVT) reaction by using the MEGAscript HighYield Transcription Kit (Ambion Inc, Austin, TX). Following in vitro transcription, $600 \mathrm{ng}$ of cRNA from each replicate was used for the second-cycle first-strand cDNA synthesis. The first-strand cDNA from the second cycle was then converted to second-strand cDNA. From second-strand cDNA template, biotin-labeled cRNA was prepared in an in vitro transcription (IVT) reaction by using GeneChip IVT Labeling Kit (Affymetrix) according to the manufacturer's instructions. Then $15 \mu \mathrm{g}$ of biotin-labeled cRNA was fragmented in $1^{\prime}$ fragmentation buffer solution provided with the GeneChip Sample Cleanup Module (Affymetrix) at $94^{\circ} \mathrm{C}$ for $35 \mathrm{~min}$. A total of $10 \mu \mathrm{g}$ of fragmented biotinlabeled cRNA per replicate in hybridization mixture was then hybridized to Porcine Genome Array from Affymetrix GeneChips and incubated overnight at $45^{\circ} \mathrm{C}$ in a rotating hybridization oven, all according to the manufacturer's instructions (Affymetrix). After $>16 \mathrm{~h}$ of hybridization, the mixture was removed, and, in several cycles, the chips were washed with nonstringent buffer and stained with streptavidin/phycoerythrin (SAPE) antibody solution according to the manufacturer's instructions by using an Affymetrix FS450 fluidics station. The data were collected using Affymetrix GeneChip Scanner 3300 (Affymetrix). Three chips were used for each experimental condition and the RNA for each chip was obtained from three different leaflets.

2.4. Statistical Analysis of Array Data. Microarray data was analyzed using a mixture model approach as previously described [18]. Briefly, microarray analysis was performed for expression differences assuming that genes in alternative treatments are expressed or not in the following combinations: (i) not expressed in either condition, (ii) expressed only under the first condition, (iii) expressed only under the second condition, and (iv) expressed under both conditions, giving rise to 4 possible clusters with two treatments. The number of these combinations/clusters was determined by Akaike's Information Criterion (AIC) and the Bayesian Information Criterion (BIC) [19, 20].

2.5. Gene Expression Analysis by Quantitative Real-Time Polymerase Chain Reaction. To confirm the fold changes in gene expression from the array data, semi-quantitative reverse transcriptase polymerase chain reaction (qRT-PCR) was done to measure the relative change in mRNA expression. Real-Time qRT-PCR was carried out with $10 \mathrm{ng}$ of total RNA using a Bio-Rad iCycler thermocycler and iScript one-step SYBR Green kit, following the manufacturer's instructions. Primer sequences (Table 1) were designed using Primer 3 software [14]. Sequences were selected that crossed intron/ exon boundaries to ensure the elimination of genomic DNA. cDNA synthesis and PCR amplification were performed using the following steps: $50^{\circ} \mathrm{C}$ for 30 mins then the reaction mixture was heated to $95^{\circ} \mathrm{C}$ for $5 \mathrm{~min}$; a 45 cycle two-step PCR was performed consisting of $95^{\circ} \mathrm{C}$ for $15 \mathrm{~s}$ followed by $1 \mathrm{~min}$ at $60^{\circ} \mathrm{C}$. Following amplification, a melt curve was generated that confirmed primer specificity. Expression values for each gene were calculated relative to $18 \mathrm{~s}$ mRNA levels. The mean fold change $(n=5)$ was calculated using the $2^{(-\Delta \Delta \mathrm{Ct})}$ method.

2.6. Network Modeling of Gene Expression Data. Affymetrix probe IDs that did not belong to the null distribution based on the mixture model analysis were mapped to Ensembl porcine gene accessions using Ensembl Biomart [21]. To identify the molecular functions, biological networks and signaling pathways in VICs responsive to cyclic pressure, pathway analysis using Ingenuity Pathways Analysis (IPA; Ingenuity Systems, California) was carried out as described previously [22]. Human orthologs for porcine genes (obtained from Biomart) were used in IPA. IPA generated networks that are no more than 35 genes/proteins in size. Based on the overlap between the genes in user dataset and a reference set (which is often the entire genome), IPA estimates the probability that genes in a network were found together due to chance. Networks scoring $\geq 2$, with $>99 \%$ confidence of not being generated by chance were considered to be significant. Annotations from scientific literature stored in the Ingenuity Pathways Knowledge Base (IPKB) were used to determine biological functions of the identified networks. Fisher exact test was used to calculate the $P$-value, the probability of each biological function/disease or pathway being assigned by chance. A $P \leq 0.05$ (adjusted for multiple testing for statistical rigorousness) was used to select highly significant biological functions and pathways represented in the gene expression datasets. 
TABLe 2: Upregulated genes related to inflammation. All genes had a $P \leq 0.001$.

\begin{tabular}{|c|c|c|c|}
\hline Ensembl Gene ID & Gene name & Description & Fold change \\
\hline ENSSSCG00000014986 & MMP3 & $\begin{array}{l}\text { Matrix metallopeptidase } 3 \text { (stromelysin } 1 \text {, } \\
\text { progelatinase) }\end{array}$ & 159.845 \\
\hline ENSSSCG00000015385 & IL6 & Interleukin 6 (interferon, beta 2) & 117.817 \\
\hline ENSSSCG00000006286 & SELE & Selectin E & 74.336 \\
\hline ENSSSCG00000011727 & PTX3 & Pentraxin 3, long & 41.052 \\
\hline ENSSSCG00000008087 & IL1B & Interleukin 1, beta & 20.185 \\
\hline ENSSSCG00000017482 & CSF3 & $\begin{array}{l}\text { Granulocyte colony-stimulating factor } \\
\text { Precursor (G-CSF) }\end{array}$ & 15.267 \\
\hline ENSSSCG00000006588 & S100A9 & S100 calcium binding protein A9 & 9.664 \\
\hline ENSSSCG00000008959 & CXCL2 & CXCL2 & 9.498 \\
\hline ENSSSCG00000008090 & IL1A & Interleukin 1, alpha & 9.361 \\
\hline ENSSSCG00000017705 & CCL5 & Chemokine (C-C motif) ligand 5 & 9.339 \\
\hline ENSSSCG00000017721 & CCL8 & Chemokine (C-C motif) ligand 8 & 8.386 \\
\hline ENSSSCG00000006288 & SELP & $\begin{array}{l}\text { Selectin P (granule membrane protein } \\
140 \mathrm{kDa} \text {, antigen CD62) }\end{array}$ & 8.002 \\
\hline ENSSSCG00000014985 & MMP1 & $\begin{array}{l}\text { Matrix metallopeptidase } 1 \text { (interstitial } \\
\text { collagenase) }\end{array}$ & 7.976 \\
\hline ENSSSCG00000008953 & IL8 & Interleukin 8 & 7.279 \\
\hline ENSSSCG00000008957 & CXCL5 & $\begin{array}{l}\text { Alveolar macrophage chemotactic factor } \\
2 \text { Precursor (Alveolar macrophage } \\
\text { chemotactic factor II) (AMCF-II) }\end{array}$ & 7.189 \\
\hline ENSSSCG00000008975 & CXCL9 & Chemokine (C-X-C motif) ligand 9 & 6.687 \\
\hline ENSSSCG00000017723 & CCL2 & Chemokine (C-C motif) ligand 2 & 5.243 \\
\hline ENSSSCG00000012853 & IRF7 & Interferon regulatory factor 7 & 4.625 \\
\hline ENSSSCG00000013655 & ICAM1 & Intercellular adhesion molecule 1 & 4.041 \\
\hline ENSSSCG00000001050 & EDN1 & Endothelin 1 & 3.383 \\
\hline ENSSSCG00000004789 & THBS1 & Thrombospondin 1 & 3.113 \\
\hline ENSSSCG00000001404 & TNF & $\begin{array}{l}\text { Tumor necrosis factor Precursor } \\
\text { (TNF-alpha)(Tumor necrosis factor } \\
\text { Ligand superfamily member } \\
\text { 2)(TNF-a)(Cachectin) }\end{array}$ & 2.626 \\
\hline ENSSSCG00000010414 & CXCL12 & Chemokine (C-X-C motif) ligand 12 & 2.62 \\
\hline ENSSSCG00000000708 & TNFRSF1A & $\begin{array}{l}\text { Tumor necrosis factor receptor } \\
\text { superfamily, member } 1 \mathrm{~A}\end{array}$ & 2.327 \\
\hline ENSSSCG00000009002 & TLR2 & Toll-like receptor 2 & 2.157 \\
\hline ENSSSCG00000003065 & PLAUR & $\begin{array}{l}\text { Plasminogen activator, urokinase } \\
\text { receptor }\end{array}$ & 1.937 \\
\hline ENSSSCG00000009477 & EDNRB & $\begin{array}{l}\text { Endothelin B receptor Precursor } \\
\text { (ET-B)(Endothelin receptor nonselective } \\
\text { type) }\end{array}$ & 1.859 \\
\hline ENSSSCG00000011942 & $\mathrm{CD} 47$ & CD47 molecule & 1.858 \\
\hline ENSSSCG00000001346 & $\mathrm{ABCF} 1$ & $\begin{array}{l}\text { ATP-binding cassette subfamily F } \\
\text { member } 1\end{array}$ & 1.786 \\
\hline ENSSSCG00000010312 & PLAU & Plasminogen activator, urokinase & 1.747 \\
\hline ENSSSCG00000013181 & SERPING1 & $\begin{array}{l}\text { Serpin peptidase inhibitor, clade G (C1 } \\
\text { inhibitor), member } 1\end{array}$ & 1.71 \\
\hline ENSSSCG00000007440 & $\mathrm{CD} 40$ & $\begin{array}{l}\text { CD } 40 \text { molecule, TNF receptor } \\
\text { superfamily member } 5\end{array}$ & 1.674 \\
\hline ENSSSCG00000004156 & IFNGR1 & Interferon gamma receptor 1 & 1.6 \\
\hline
\end{tabular}


TABle 2: Continued.

\begin{tabular}{lclc}
\hline Ensembl Gene ID & Gene name & Description & Fold change \\
\hline ENSSSCG00000001849 & ANPEP & Alanyl (membrane) aminopeptidase & 1.547 \\
ENSSSCG00000011322 & CCR1 & Chemokine (C-C motif) receptor 1 & 1.542 \\
ENSSSCG00000000244 & PPBP & $\begin{array}{l}\text { Platelet basic protein Precursor } \\
\text { (PBP)(C-X-C motif chemokine }\end{array}$ & 1.533 \\
ENSSSCG00000013551 & & 7)(Small-inducible cytokine B7) & 1.514 \\
\hline
\end{tabular}

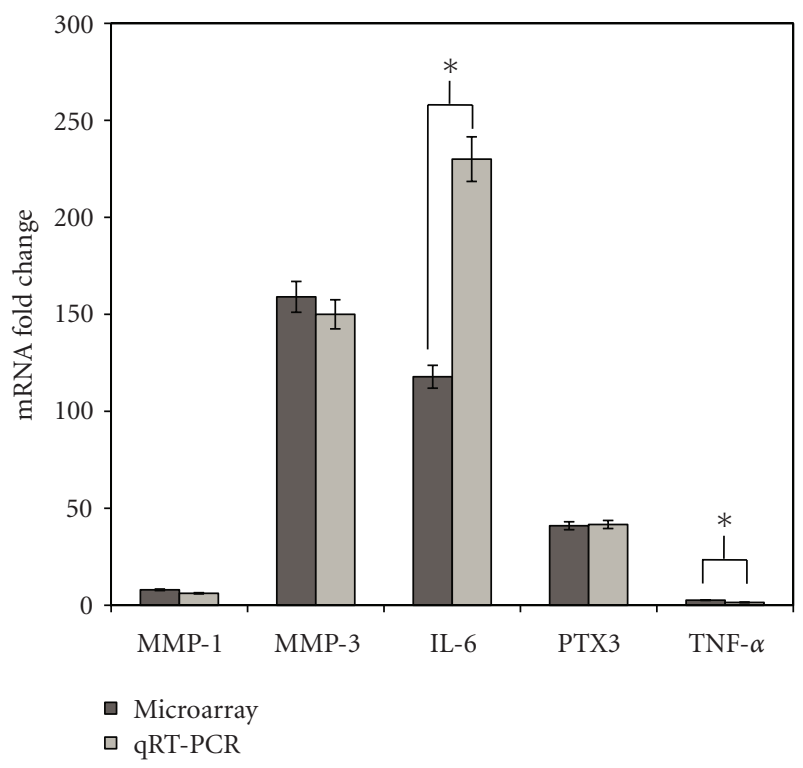

FIGURE 4: Confirmation of microarray data by real-time qRT-PCR. The fold change in gene expression was significantly higher in VICs exposed to elevated pressure compared to VICs exposed to normal cyclic pressure. ${ }^{*}$ Represents a significant difference between microarray and qRT-PCR data.

\section{Results}

Transcriptome analysis of VICs was performed to determine the distinct genetic profile of VICs exposed to $80 \mathrm{mmHg}$ (control) and $120 \mathrm{mmHg}$ cyclic pressure. The mixture model method was used as a preliminary tool to cluster genes that could be important for the biology under investigation. In this analysis, 3 clusters with $49.8 \%$ of the differences in the null cluster were found, meaning that approximately $50 \%$ of the transcriptome was impacted by treatments to some degree. However, only $\sim 6,000$ of those genes could be differentiated from the null cluster with high probability $(P<$ $0.0001)$. The microarray data was validated at the mRNA level by qRT-PCR (Figure 4). Based on the microarray data, we chose three genes known to be mechanosensitive and associated with aortic stenosis: MMP-1, MMP-3, and IL-6. Further, MMP3 and IL6 had the highest fold change detected by microarray. qRT-PCR was also performed on PTX3 and TNF- $\alpha$, as these were key genes identified in the network analysis. Upregulation of all five genes in response to elevated pressure found in the microarray was confirmed by qRTPCR. There was a significant difference in the fold change of IL6 and TNF- $\alpha$; however, microarray and qRT-PCR both showed these genes to be upregulated in the presence of elevated pressure. A pathway analysis using IPA was completed to provide the basis for determining molecular functions, pathways, and networks that were important for the VIC response to altered pressure. IPA analysis showed that 56 genes related to inflammation were differentially expressed; 35 of these genes were up regulated and 21 genes were downregulated, as shown in Tables 2 and 3, respectively. At the chosen statistical thresholds, 16 networks were identified. The network centered on tumor necrosis factor (TNF$\alpha)$ that included molecules involved in the inflammatory response is shown in Figure 5. This network included all genes differentially expressed by elevated pressure, as shown in Tables 2 and 3.

\section{Discussion}

The limited success of antiatherosclerotic therapies and the realization that distinct differences exist between the pathogenesis of atherosclerosis and AS suggests that innovative pharmacotherapies are needed. Analysis of gene expression changes in the context of response, networks, and pathways can expedite understanding of the molecular mechanisms that govern the VIC response to pressure. In the present study, novel molecular mechanisms that are activated in VICs during exposure to elevated pressure conditions were identified. Our results show that elevated pressure induces a gene expression pattern in cells that is considerably similar to that seen in aortic valve disease [1], in terms of altered expression of ECM proteins (MMP-1, MMP-3) $[23,24]$ and proinflammatory cytokines (IL-1 $\beta$, IL-6) $[15,25,26]$. These results underline the key role of hypertension as an initiating factor in the onset of aortic valve pathogenesis. Modeling these genes to identify networks has facilitated the discovery of some very specific genes that could potentially be targeted for the treatment of aortic heart valve disease.

Previous histological studies of stenotic valves show that TNF- $\alpha$ and IL- 6 both colocalize with ox-LDL. These tend to localize in the fibrosa at the vicinity of calcified areas [14]. Hence, the findings from the microarray data are supported by clinical observations. Creation of the gene network model provides a systems view of the molecular mechanisms and enables us to identify how various genes interact. TNF- $\alpha$ expression was increased under elevated pressure conditions and appears to be a key molecule in this network as it promotes expression of several adhesion molecules, including E-selectin, P-selectin, and ICAM-1. 


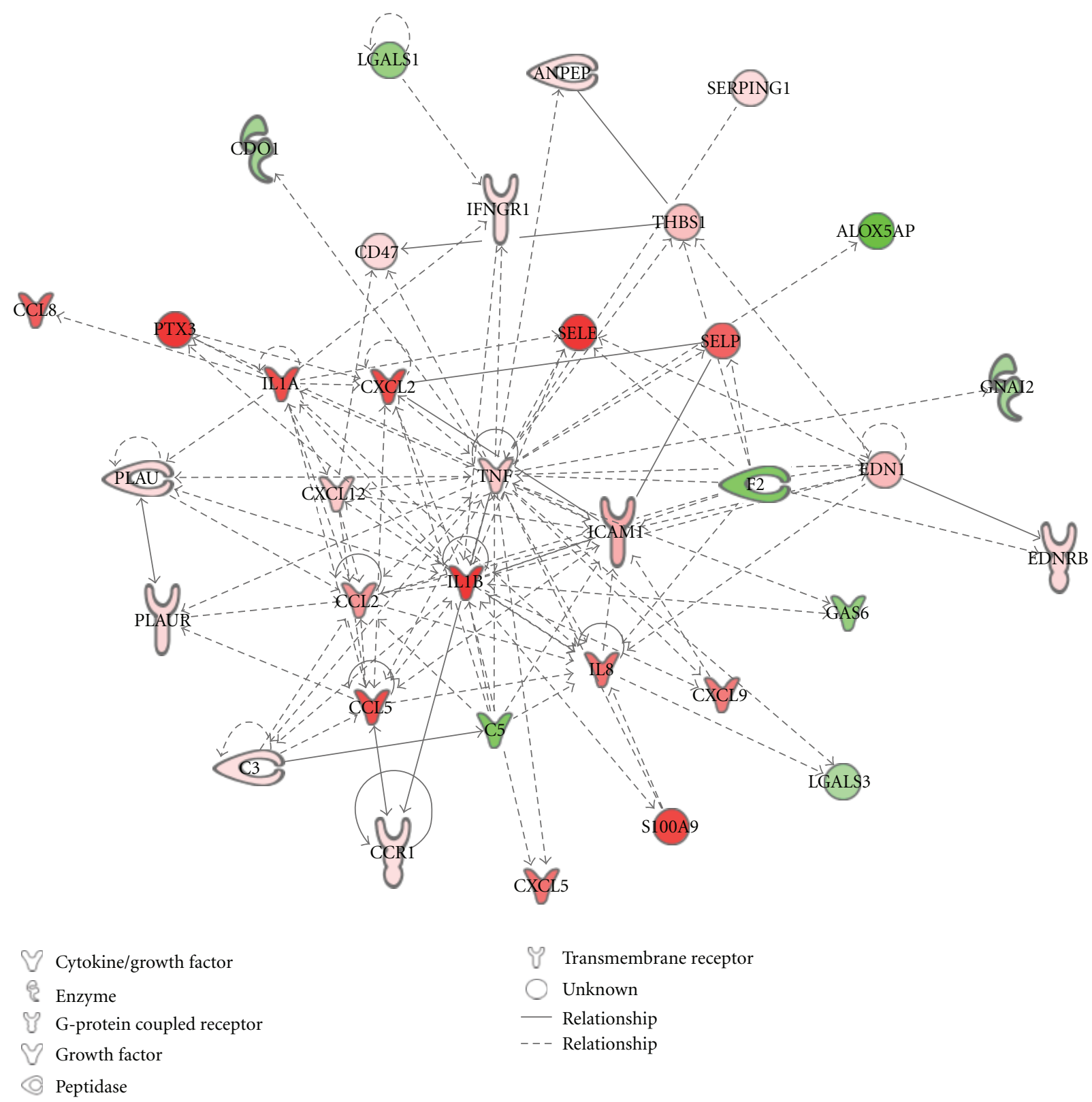

FIGURE 5: Inflammatory gene network associated with upregulation of TNF $\alpha$. In the network, green represents genes with reduced expression while pink and red nodes denote a significant increase in gene expression.

Although adhesion molecules are more typically associated with endothelial cells, it is known that activated vascular smooth muscle cells can express adhesion molecules as part of the inflammatory process [27]. TNF- $\alpha$ also interacts with the cytokines IL- $1 \alpha$ and IL- $1 \beta$. Cytokine-targeting therapy that specifically targets TNF- $\alpha$, IL- 1 , or IL-6 could be an effective antiinflammatory treatment for retarding disease progression. IL- $1 \alpha$ and IL- $1 \beta$ promote the expression of long-chain pentraxin 3 (PTX3). Clinical studies have also shown that PTX3 levels are elevated in AS patients [28]. The short chain pentraxin, C-reactive protein, has been offered as an early diagnostic marker for cardiovascular diseases. However, because it can be produced in several organs, its reliability has been questioned. PTX3 could be a potential alternative, especially heart valve disease, and it has been proposed as a new candidate marker for acute and chronic heart diseases [29]. PTX3 is also involved in controlling inflammation and tissue remodeling and could therefore be a potential candidate for early AS therapy. Recent studies have shown that PTX3 has a nonredundant regulatory and cardioprotective role in acute myocardial infarction in mice [30].

The results of the present study are consistent with our global hypothesis that elevated pressure contributes to the development of aortic valve disease. However, certain limitations of the present study should be acknowledged. First, the small sample for microarray analysis may decrease the sensitivity of the study. However, the Mean-DifferenceMixture-Model (MD-MM) method used for statistical analysis is generally superior to other methods in most situations. 
TABLE 3: Down regulated genes related to inflammation. All genes had a $P \leq 0.001$.

\begin{tabular}{|c|c|c|c|}
\hline Ensembl gene ID & Gene name & Description & Fold change \\
\hline ENSSSCG00000005055 & LGALS3 & Lectin, galactoside-binding, soluble, 3 & -1.575 \\
\hline ENSSSCG00000011993 & PROS1 & Protein S (alpha) & -1.654 \\
\hline ENSSSCG00000011399 & GNAI2 & $\begin{array}{l}\text { Guanine nucleotide binding protein ( } \mathrm{G} \\
\text { protein), alpha inhibiting activity } \\
\text { polypeptide } 2\end{array}$ & -1.69 \\
\hline ENSSSCG00000001408 & AIF1 & $\begin{array}{l}\text { Allograft inflammatory factor } 1 \\
\text { (AIF-1)(Ionized calcium-binding adapter } \\
\text { molecule 1)(Protein G1) }\end{array}$ & -1.715 \\
\hline ENSSSCG00000014310 & CXCL14 & Chemokine (C-X-C motif) ligand 14 & -1.73 \\
\hline ENSSSCG00000013030 & PRDX5 & Peroxiredoxin 5 & -1.751 \\
\hline ENSSSCG00000014219 & CDO1 & Cysteine dioxygenase, type I & -1.791 \\
\hline ENSSSCG00000012840 & CD151 & CD151 molecule (Raph blood group) & -1.851 \\
\hline ENSSSCG00000015997 & PRKRA & $\begin{array}{l}\text { Protein kinase, interferon-inducible } \\
\text { double stranded RNA dependent } \\
\text { activator pseudogene } 1\end{array}$ & -1.927 \\
\hline ENSSSCG00000006612 & S100A10 & S100 calcium binding protein A10 & -1.937 \\
\hline ENSSSCG00000007982 & MPG & N-methylpurine-DNA glycosylase & -1.949 \\
\hline ENSSSCG00000015570 & IVNS1ABP & Influenza virus NS1A binding protein & -1.963 \\
\hline ENSSSCG00000014170 & CAST & Calpastatin & -2.067 \\
\hline ENSSSCG00000006661 & VPS45 & $\begin{array}{l}\text { Vacuolar protein sorting } 45 \text { homolog (S. } \\
\text { cerevisiae) }\end{array}$ & -2.105 \\
\hline ENSSSCG00000000125 & LGALS1 & Lectin, galactoside-binding, soluble, 1 & -2.133 \\
\hline ENSSSCG00000009565 & GAS6 & Growth arrest-specific 6 & -2.193 \\
\hline ENSSSCG00000008428 & MSH2 & MutS homolog 2 & -2.509 \\
\hline ENSSSCG00000013252 & $\mathrm{F} 2$ & $\begin{array}{l}\text { Prothrombin Precursor (EC 3.4.21.5) } \\
\text { (Coagulation factor II) }\end{array}$ & -2.746 \\
\hline ENSSSCG00000005512 & $\mathrm{C} 5$ & Complement component 5 & -2.793 \\
\hline ENSSSCG00000017473 & TOP2A & Topoisomerase (DNA) II alpha $170 \mathrm{kDa}$ & -4.029 \\
\hline ENSSSCG00000009330 & ALOX5AP & $\begin{array}{l}\text { Arachidonate 5-lipoxygenase-activating } \\
\text { protein }\end{array}$ & -4.058 \\
\hline
\end{tabular}

The method is particularly advantageous in situations where there are few replicates, poor signal to noise ratios, or nonhomogenous variances [18]. Second, the amount of total RNA isolated from tissue was insufficient for microarray analysis without nonlinear amplification. Therefore, a twocycle amplification was necessary to increase the amount of cRNA for testing. Alternative methods of RNA isolation, such as the Qiagen lipid kit, may alleviate this limitation in future studies. As valve leaflets were only exposed to pressure, we did not address the potentially important role of other mechanical factors that are part of the valve mechanical environment in vivo such as tensile and compressive strain, shear stress, and flexure. When these forces are combined, they could potentially have an antagonistic or a synergistic effect. Another limitation in our study is our Pathway analysis using IPA. While IPA helped in identifying molecular networks responsive to elevated pressure in VICs, it failed to capture species-specific information that could be pertinent to effects of pressure on VICs. Furthermore, information within IPA knowledge base is obtained from scientific literature, and thus gene functions and interactions are subject to the last update of the software.
To obtain a pure population of VICs, the endothelium was removed from leaflets. Endothelial denudation may have multiple effects on the biology of the tissue. It has been proposed that alterations in the mechanical environment of the leaflets could be transduced into a pathobiological response via a two-way communication system between endothelial and interstitial cells. Denudation disrupts this communication and may expose the subendothelial interstitial cells to mechanical stimuli that they do not see when the endothelium is intact. This limitation would also be present in cell culture; however, by using an organ culture system, VICs were retained in their native three-dimensional ECM. The ECM is important for the transmission of mechanical signals to cells and thus, this system has a distinct advantage over mechanical studies performed with isolated cells. The alternative is in vivo studies. Although these have greater physiological relevance, they do not allow for strict mechanical characterization or isolation of the effects of pressure.

In conclusion, pressure-induced changes in the porcine aortic valve interstitial cell transcriptome are reported. This study provides rationale for further investigation of highly 
connected and highly regulated genes as potential therapeutic targets.

\section{Acknowledgments}

This work was supported by the American Heart Association National Affiliate through a Scientist Development Grant $(0835136 \mathrm{~N}$ to J. N. Warnock). The authors gratefully acknowledge the technical assistance of Alex Ruhl with analysis of the qRT-PCR gene expression data and Toi Spates for assistance with histology.

\section{References}

[1] Y. Bossé, P. Mathieu, and P. Pibarot, "Genomics: the next step to elucidate the etiology of calcific aortic valve stenosis," Journal of the American College of Cardiology, vol. 51, no. 14, pp. 1327-1336, 2008.

[2] J. T. Butcher, C. A. Simmons, and J. N. Warnock, "Mechanobiology of the aortic heart valve," Journal of Heart Valve Disease, vol. 17, no. 1, pp. 62-73, 2008.

[3] C. M. Otto, B. K. Lind, D. W. Kitzman, B. J. Gersh, and D. S. Siscovick, "Association of aortic-valve sclerosis with cardiovascular mortality and morbidity in the elderly," The New England Journal of Medicine, vol. 341, no. 3, pp. 142-147, 1999.

[4] N. M. Rajamannan, B. Gersh, and R. O. Bonow, "Calcific aortic stenosis: from bench to the bedside-emerging clinical and cellular concepts," Heart, vol. 89, no. 7, pp. 801-805, 2003.

[5] J. Ross Jr. and E. Braunwald, "Aortic stenosis," Circulation, vol. 38, no. 1, pp. 61-67, 1968.

[6] P. J. Cawley and C. M. Otto, "Prevention of calcific aortic valve stenosis-fact or fiction?” Annals of Medicine, vol. 41, no. 2, pp. 100-108, 2009.

[7] L. A. Cuniberti, P. G. Stutzbach, E. Guevara, G. G. Yannarelli, R. P. Laguens, and R. R. Favaloro, "Development of mild aortic valve stenosis in a rabbit model of hypertension," Journal of the American College of Cardiology, vol. 47, no. 11, pp. 2303-2309, 2006.

[8] M. O. Platt, Y. Xing, H. Jo, and A. P. Yoganathan, "Cyclic pressure and shear stress regulate matrix metalloproteinases and cathepsin activity in porcine aortic valves," Journal of Heart Valve Disease, vol. 15, no. 5, pp. 622-629, 2006.

[9] J. N. Warnock, S. C. Burgess, A. Shack, and A. P. Yoganathan, "Differential immediate-early gene responses to elevated pressure in porcine aortic valve interstitial cells," Journal of Heart Valve Disease, vol. 15, no. 1, pp. 34-41, 2006.

[10] Y. Xing, Z. He, J. N. Warnock, S. L. Hilbert, and A. P. Yoganathan, "Effects of constant static pressure on the biological properties of porcine aortic valve leaflets," Annals of Biomedical Engineering, vol. 32, no. 4, pp. 555-562, 2004.

[11] Y. Xing, J. N. Warnock, Z. He, S. L. Hilbert, and A. P. Yoganathan, "Cyclic pressure affects the biological properties of porcine aortic valve leaflets in a magnitude and frequency dependent manner," Annals of Biomedical Engineering, vol. 32, no. 11, pp. 1461-1470, 2004.

[12] W. D. Merryman, I. Youn, H. D. Lukoff et al., "Correlation between heart valve interstitial cell stiffness and transvalvular pressure: implications for collagen biosynthesis," American
Journal of Physiology-Heart and Circulatory Physiology, vol. 290, no. 1, pp. H224-H231, 2006.

[13] N. M. Rajamannan, R. O. Bonow, and S. H. Rahimtoola, "Calcific aortic stenosis: an update," Nature Clinical Practice Cardiovascular Medicine, vol. 4, no. 5, pp. 254-262, 2007.

[14] N. Côté, P. Pibarot, A. Pépin et al., "Oxidized low-density lipoprotein, angiotensin II and increased waist cirumference are associated with valve inflammation in prehypertensive patients with aortic stenosis," International Journal of Cardiology, vol. 145, no. 3, pp. 444-449, 2010.

[15] J. J. Kaden, C. E. Dempfle, R. Grobholz et al., "Inflammatory regulation of extracellular matrix remodeling in calcific aortic valve stenosis," Cardiovascular Pathology, vol. 14, no. 2, pp. 8087, 2005.

[16] K. D. O’Brien, "Pathogenesis of calcific aortic valve disease: a disease process comes of age (and a good deal more)," Arteriosclerosis, Thrombosis, and Vascular Biology, vol. 26, no. 8, pp. 1721-1728, 2006.

[17] C. H. Yap, H. S. Kim, K. Balachandran, M. Weiler, R. Haj-Ali, and A. P. Yoganathan, "Dynamic deformation characteristics of porcine aortic valve leaflet under normal and hypertensive conditions," American Journal of Physiology-Heart and Circulatory Physiology, vol. 298, no. 2, pp. H395-H405, 2010.

[18] W. M. Muir, G. J. M. Rosa, B. R. Pittendrigh et al., "A mixture model approach for the analysis of small exploratory microarray experiments," Computational Statistics and Data Analysis, vol. 53, no. 5, pp. 1566-1576, 2009.

[19] H. Akaike, "A new look at the statistical model identification," IEEE Transactions on Automatic Control, vol. 19, no. 6, pp. 716-723, 1974.

[20] G. Schwarz, "Estimating the dimension of a model," Annals of Statisitcs, vol. 6, pp. 461-464, 1978.

[21] S. Haider, B. Ballester, D. Smedley, J. Zhang, P. Rice, and A. Kasprzyk, "BioMart central portal-unified access to biological data," Nucleic Acids Research, vol. 37, no. 2, pp. W23-W27, 2009.

[22] D. Peddinti, B. Nanduri, A. Kaya, J. M. Feugang, S. C. Burgess, and E. Memili, "Comprehensive proteomic analysis of bovine spermatozoa of varying fertility rates and identification of biomarkers associated with fertility," BioMed Central Systems Biology, vol. 2, no. 1, p. 19, 2008.

[23] S. A. Dreger, P. M. Taylor, S. P. Allen, and M. H. Yacoub, "Profile and localization of matrix metalloproteinases (MMPs) and their tissue inhibitors (TIMPs) in human heart valves," Journal of Heart Valve Disease, vol. 11, no. 6, pp. 875-880, 2002.

[24] M. E. Edep, J. Shirani, P. Wolf, and D. L. Brown, "Matrix metalloproteinase expression in nonrheumatic aortic stenosis," Cardiovascular Pathology, vol. 9, no. 5, pp. 281-286, 2000.

[25] K. Akat, M. Borggrefe, and J. J. Kaden, "Aortic valve calcification: basic science to clinical practice," Heart, vol. 95, no. 8, pp. 616-623, 2009.

[26] J. J. Kaden, C. E. Dempfle, R. Grobholz et al., "Interleukin1 beta promotes matrix metalloproteinase expression and cell proliferation in calcific aortic valve stenosis," Atherosclerosis, vol. 170, no. 2, pp. 205-211, 2003.

[27] V. J. Dzau, R. C. Braun-Dullaeus, and D. G. Sedding, "Vascular proliferation and atherosclerosis: new perspectives and therapeutic strategies," Nature Medicine, vol. 8, no. 11, pp. 12491256, 2002.

[28] Y. Naito, T. Tsujino, H. Akahori et al., "Increase in tissue and circulating pentraxin3 levels in patients with aortic valve stenosis," American Heart Journal, vol. 160, no. 4, pp. 685-691, 2010. 
[29] M. Nebuloni, F. Pasqualini, P. Zerbi et al., "PTX3 expression in the heart tissues of patients with myocardial infarction and infectious myocarditis," Cardiovascular Pathology, vol. 20, no. 1, pp. e27-e35, 2011.

[30] M. Salio, S. Chimenti, N. D. Angelis et al., "Cardioprotective function of the long pentraxin PTX3 in acute myocardial infarction," Circulation, vol. 117, no. 8, pp. 1055-1064, 2008. 


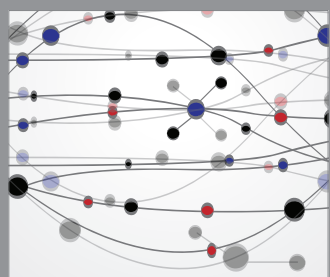

The Scientific World Journal
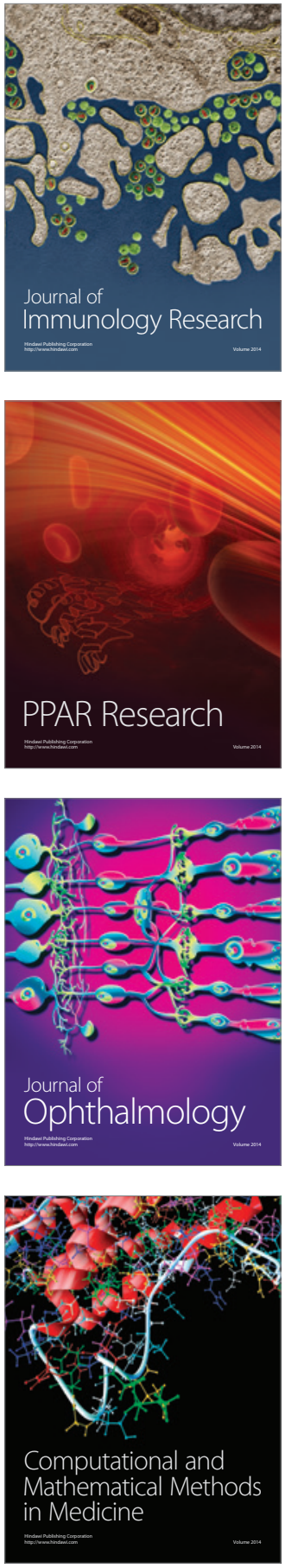

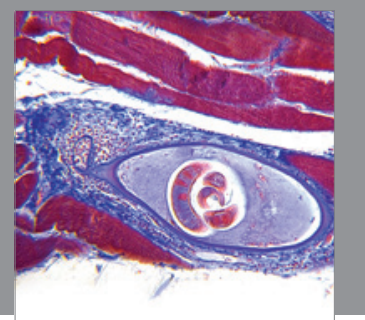

Gastroenterology

Research and Practice
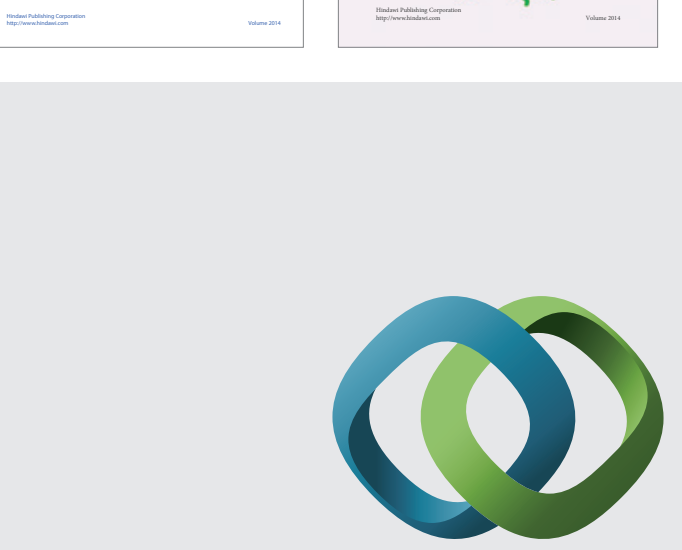

\section{Hindawi}

Submit your manuscripts at

http://www.hindawi.com
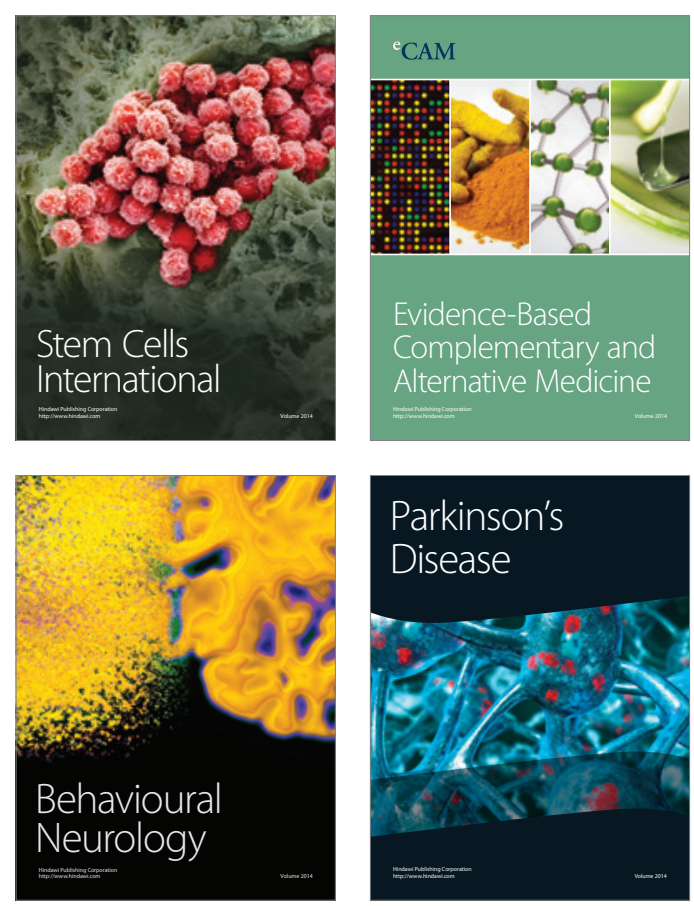

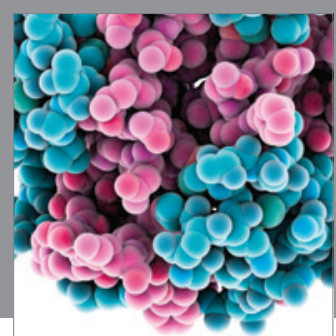

Journal of
Diabetes Research

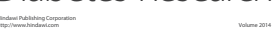

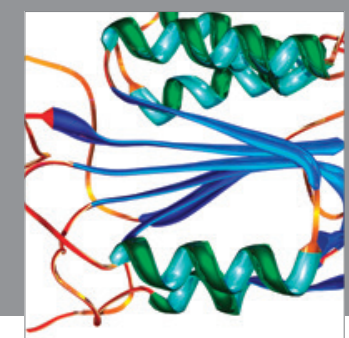

Disease Markers
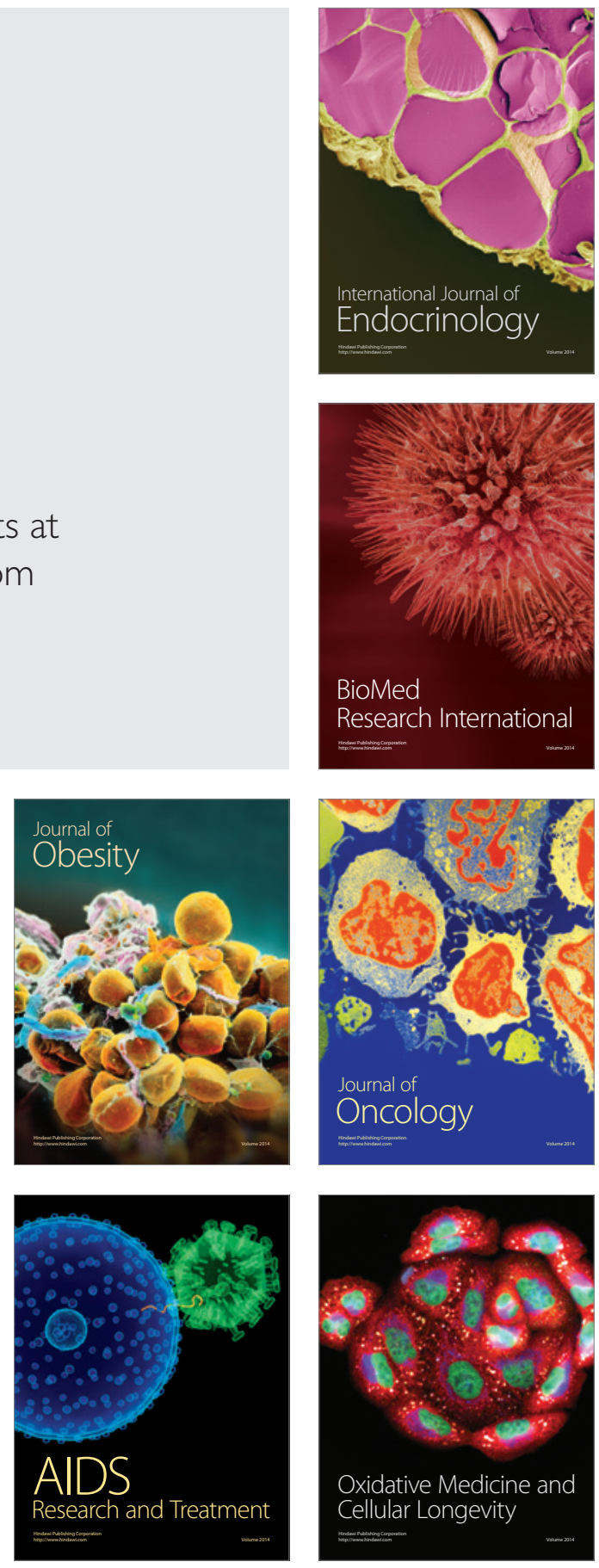